\title{
Risk and Uncertainty Revisited: A Clarification of Theory and Application
}

\author{
M. J. Alhabeeb ${ }^{1}$ \\ ${ }^{1}$ Department of Resource Economics, University of Massachusetts, Amherst MA 01003, USA \\ Correspondence: M. J. Alhabeeb, Department of Resource Economics, University of Massachusetts, Amherst \\ MA 01003, USA.
}

Received: October 10, 2021

Accepted: November 16, 2021

Online Published: November 28, 2021

doi:10.5539/ijef.v14n1p1

URL: https://doi.org/10.5539/ijef.v14n1p1

\begin{abstract}
In addition to the obvious public confusion and lack of distinction between the terms, risk and uncertainty and other related concepts, the interchangeable use seems to seep into the academic and professional research. According to a 2018 study by De Groot and Thurik, it was reported that $88.3 \%$ of articles in this topic, across the related fields, did not adhere to the distinction between risk and uncertainty, rendering all the undesirable theoretical and empirical consequences. This paper is intended to revisit the concepts of risk and uncertainty, not only clarifying the meaning and use of the terms, but also shedding a light on differentiating all the related concepts. The focus is on risk, being the core element directly related to the success and failure of all financial and managerial decision making. The approach is not only conceptual, but also supported by mathematical and numerical applications.
\end{abstract}

Keywords: risk, uncertainty, ambiguity, risk aversion, uncertainty avoidance

\section{Introduction}

How certain can we be of the nature and direction of the consequences to any decision we make? The rational answer would most likely be that we cannot be one hundred percent sure! but some degree of certainty can be discerned, analyzed, and estimated, along with some uncertainty, ambiguity, and risk. Some of our decisions are made under the right circumstances that allow for an excellent degree of certainty, while other decisions are made under less fortunate circumstances, allowing different degrees of uncertainty and risky conditions. However, life experience shows that there has always been an atmosphere of uncertainty and risk surrounding all decisions, no matter how well-suited the circumstances, how well-deliberated the process, and how much checks and calculations were made. Experience has also shown that success and failure can be determined by how all potential factors of risk and uncertainty are recognized and accounted for. There has been a considerable amount of research done on this very subject, namely the process of decision making under the condition of risk and uncertainty, but surprisingly most of the published studies, not only did not distinguish between risk and certainty, but also neglected to recognize the other related concepts and constructs, and therefore underestimate their role in determining the outcome. Groot and Thurik (2018) reported that, " $88.3 \%$ of articles in this topic does not adhere to the distinction between risk and uncertainty" (p. 4)! Not to mention the distinction among other related terms that are assumed to be interchangeable. The authors continue to declare that not distinguishing between these closely related terms would "contribute to the contamination of the concepts that currently dominate the literature and make research prone to confusion and may lead researchers to erroneous conclusions" (p. 5), and undesirable theoretical and empirical consequences.

The objective of this study is to revisit and clarify major concepts and important theoretical constructs that have been sometimes used in an equivocal way and applied in a misleading manner. It shed a light on differentiating risk and uncertainty and all other sub- terms and related constructs. The focus is specifically on risk, being the core construct directly related to the financial and managerial decisions. The approach is conceptual and supported by mathematical and numerical applications.

\section{Differentiating the Interrelated Concepts}

The most relevant meanings of risk and its related concepts come in the context of economics. It goes back to the American economist Frank Knight (1885-1972) and his 1921 study on risk and uncertainty and profit. Certainty 
in this context refers to the condition of having one possible outcome that is known and absolutely confirmed to the decision maker. Contrary to that, and whenever there is a possibility of having more than one outcome, the condition would be considered either risky or uncertain. This would lead us to the distinction between risk and uncertainty, the two terms that may have been used interchangeably all along despite having a thin but crucial line between them, especially in the context of managerial and financial considerations.

Risk refers to the condition in which there are multiple possible outcomes, where the probability of each alternative outcome is either known or can be estimated. Uncertainty shares the first element with risk, which is the existence of multiple possible outcomes, but differs in the second element such that the probability of each outcome is either unknown or cannot be estimated. Uncertainty includes two types: Total uncertainty is where conditions are entirely unknown and there is no guidance to their inference, while Partial uncertainty leaves the possibility of inference to a set of subjective assumptions. This partial uncertainty is treated like the risky conditions in the context of managerial decisions. Differentiating the concepts would imply the distinction between their sub-terms such as risk aversion and uncertainty aversion. Risk aversion refers generally to avoiding the unknown, which leads to preferring higher predictability over low predictability of outcomes. Uncertainty aversion, which is also sometimes called Ambiguity aversion is about the preference of plainly known chance over any unknown chance, even when the reward of the known chance is less than the reward of the unknown chance. (Kahn \& Sarin, 1988). This concept can be illustrated by what became known as Ellsberg Paradox (Ellsberg, 1961). Uncertainty avoidance is another term that became specifically associated with social and cultural contexts, where societies and cultures are differentiated based on how tolerating they are to unpredictability in the social and cultural changes. In other words, how comfortable a society or culture is with the unknown, unconfirmed, or unconventional norms, ideas, and practices? Another related but relatively modern term is Loss aversion, which has been associated with the 1991 study by Tversky and Kahneman (Baker \& Carson, 1975; Kahneman \& Tversky, 1979; Tversky \& Kahneman, 1992). It refers to the unequitable extent of dissatisfaction/satisfaction related to the loss/gain of an equal monetary sum. In other words, it is about people's general tendency to avoid a loss, even if there is a gain of the same amount to even it out! It is simply because their dissatisfaction with the loss exceeds their satisfaction with the gain of the same amount. This logic is consistent with the economic theory of the diminishing marginal utility of wealth which suggests that a person's utility would drop more if a dollar were lost than it would rise if a dollar is gained (Bell, 1985; Kim et al., 2015).

\section{Ellsberg Paradox}

Following earlier notions of Keynes and others, American economist Daniel Ellsberg popularized this paradox about people's preference of choices with seemingly clear likelihood over choices with less clear likelihood. Ellsberg (1961). His experiment involved people's choices of two urns, each of which contains 100 balls. People were told that the first urn contains 50 red balls and 50 black balls, while the second urn contains unknown mix of red and black balls. A reward would be given to anyone who can pull a red ball from one of the urns! People have overwhelmingly chosen the first urn to pull from! Obviously, because they realized that the chance is $50 \%$ to get a red ball from the first urn, while it is unknown in the second urn. This illustrates that people dismissed the $99 \%$ probability of getting a red ball from the second urn, if it happened that there were 99 red ball and only one black ball, which was possible since the urn could contain any mix.

\section{Sources of Risk}

Many possible sources can introduce certain conditions of risk into the decision-making process. Most of these sources are external to the firm. We can group the most common sources into three categories: Economic Sources, which are related to the economic environment of a country. The fluctuations in the financial market pose a credible risk to the value of assets in the current and future periods. Such a risk is known as "market risk". Major economic factors such as inflation and interest rate pose, yet other significant impact on prices and value of lending and borrowing and their effects on earnings. Changes in the credit obligations, and in the state of liquidity can also introduce what are called credit risk and liquidity risk in addition to the currency risk which can stem from changes in the exchange rate between the domestic and foreign currencies. Also, the state of competition in the same industry or region poses another type of economic risk. Political Sources are related to the government policies, domestically and internationally, that may introduce certain risk on a certain industry, or on the entire economy. Changes in tax policies is a typical example, and expropriation risk is another example. This risk arises where a government abroad seizes a property, restricts the rights, or remove the privileges of the hosted firm. Terrorism and cybercrimes nowadays constitute a significant political risk on business activities of all firms, domestically and globally. Social Sources are related to cultural or religious reasons or to certain social norm or trend that affect consumer preferences and demand. Certain food or clothing items or weather-related products may not have any chance to be marketed in certain countries, which is a risk to 
be accounted for. Even domestically, consumer taste and preferences are subject to change and any business that cannot respond and keep up with those changes would face the risk of being outdated or off-trend and may lose its market share. International Sources are related to commercially or politically competitive reasons among countries (Alhabeeb, 2013; Baltussen et al., 2016).

\section{Measurement of Risk}

As it involves calculable multiple outcomes, risk can be defined in terms of the variability of those outcomes and to what extent they are dispersed. The relationship between risk and variability and dispersion of outcomes is direct. Large variability and wide dispersion would mean higher risk and small variability and tight distribution of outcomes indicates lower risk. For example, if an investment opportunity earns 5\% fixed and guaranteed rate of return, and another opportunity may earn anywhere between $-10 \%$ and $30 \%$, we can easily discern that it would be considered risk free in the first opportunity and risky in the second opportunity. Such a realization of that risk is based on the wide range of possibilities of the earned return in the second opportunity. Ironically, in considering this example, we can also vividly see that the only possibility of earning the high return of $30 \%$ would be available only with the risky package, hence the direct relationship between risk and return! higher return is associated with higher risk. This is to say that seeking higher return means the willingness to deal with higher risk and seeking security means accepting a modest return. Risk, therefore, can be measured by the classic statistical measurement of dispersion. That is variance or standard deviation. We can classify risk measures into an absolute and relative measure of risk. The objective of the absolute measure is to see how the actual outcome is deviating from the expected value. Can we guess how risky some assets by only looking at their returns? Let's contemplate the range of returns for $\mathrm{X}$ and $\mathrm{Y}$ assets (Table 1) and take it as a hint to the dispersion of returns, and let's assume that there are three returns for each. We can see, in the following table, that the difference between the highest and lowest return for each would refer to more dispersion for asset $\mathrm{Y}$ (range: 15 $5=10$ ), than for asset $\mathrm{X}$ (range: $11-9=2$ ). This may indicate that asset $\mathrm{Y}$ is riskier than asset $\mathrm{X}$ for having higher variability of returns.

Table 1. Range of return for asset $\mathrm{X}$ vs. asset $\mathrm{Y}$.

\begin{tabular}{ccc}
\hline Return & $\mathrm{X}$ & $\mathrm{Y}$ \\
\hline $\mathrm{k}_{1}$ & 9 & 5 \\
$\mathrm{k}_{2}$ & 11 & 10 \\
$\mathrm{k}_{3}$ & 11 & 15 \\
Range: $\mathrm{k}_{3}-\mathrm{k}_{1}$ & 2 & 10 \\
\hline
\end{tabular}

This simple variability notion can better be represented by the probability distribution of returns. The tighter the probability distribution, the more likely to have the actual return be close to the expected value, and therefore the lower the risk for that asset, and vice versa. The statistical variance $\left(\sigma^{2}\right)$ would provide a measure of variability or dispersion for it is the weighted average of the squared deviations from the mean:

$$
\sigma^{2}=\sum_{\mathrm{i}=1}^{\mathrm{n}}[\mathrm{x}-\overline{\mathrm{x}}]^{2} \mathrm{P}(\mathrm{x}) ; \overline{\mathrm{x}}=\text { Expected Value }=\sum_{\mathrm{i}=1}^{\mathrm{n}} \mathrm{x}_{\mathrm{i}} \mathrm{P}\left(\mathrm{x}_{\mathrm{i}}\right)
$$

where $\overline{\mathrm{X}}$ is the mean or the expected value of outcomes? Risk as expressed by variability or dispersion of outcomes can also be measured by the standard deviation $(\sigma)$ as it is the squared root of variance $\left(\sigma^{2}\right)$ :

If we assume the probabilities of the returns to $\mathrm{X}$ and $\mathrm{Y}$ assets are $25 \%, 50 \%$, and $25 \%$ respectively (Table 2), we can calculate the standard deviations for the three returns.

The standard deviation of .71 means that the returns on asset $\mathrm{X}$ are much closer to their own expected value than the returns on asset $Y$ which has a standard deviation of 3.5, indicating how wide the dispersion of returns.

In the long run, asset risk would be an increasing function of time. 
Table 2. Variability of the returns to two assets, $\mathrm{X}$ and $\mathrm{Y}$

\begin{tabular}{|c|c|c|c|c|c|c|}
\hline \multirow{3}{*}{$\begin{array}{c}\text { Asset } \\
\text { X }\end{array}$} & $\mathrm{x}_{\mathrm{i}}$ & $\mathrm{P}\left(\mathrm{x}_{\mathrm{i}}\right)$ & $\mathrm{x}_{\mathrm{i}} \mathrm{P}\left(\mathrm{x}_{\mathrm{i}}\right)$ & $\mathrm{x}_{\mathrm{i}}-\overline{\mathrm{x}}$ & {$\left[\mathrm{x}_{\mathrm{i}}-\overline{\mathrm{x}}\right]^{2}$} & {$\left[x_{i}-\bar{x}\right] P\left(x_{i}\right)$} \\
\hline & 9 & .25 & 2.25 & -1 & 1 & .25 \\
\hline & 10 & .50 & 5.0 & 0 & 0 & 0 \\
\hline \multirow{6}{*}{$\begin{array}{c}\text { Asset } \\
\text { Y }\end{array}$} & 11 & .25 & 2.75 & 1 & 1 & .25 \\
\hline & \multicolumn{3}{|c|}{$\overline{\mathrm{x}}=\Sigma \mathrm{x}_{\mathrm{i}} \mathrm{P}\left(\mathrm{x}_{\mathrm{i}}\right)=10$} & \multicolumn{3}{|c|}{$\sigma^{2}=\Sigma\left[\mathrm{x}_{\mathrm{i}}-\overline{\mathrm{x}}\right]^{2} \mathrm{P}\left(\mathrm{x}_{\mathrm{i}}\right)=.5$} \\
\hline & 5 & .25 & 1.25 & -5 & 25 & 6.25 \\
\hline & 10 & .50 & 5 & 0 & 0 & 0 \\
\hline & 15 & .25 & 3.75 & 5 & 25 & 6.25 \\
\hline & \multicolumn{3}{|c|}{$\overline{\mathrm{x}}=\Sigma \mathrm{x}_{\mathrm{i}} \mathrm{P}\left(\mathrm{x}_{\mathrm{i}}\right)=10$} & \multicolumn{3}{|c|}{$\sigma^{2}=\Sigma\left[\mathrm{x}_{\mathrm{i}}-\overline{\mathrm{x}}\right]^{2} \mathrm{P}\left(\mathrm{x}_{\mathrm{i}}\right)=12.5$} \\
\hline
\end{tabular}

$$
\begin{gathered}
\sigma_{x}=\sqrt{.5}=.71 ; \sigma_{y}=\sqrt{12.5}=3.5 \\
\sigma=\sqrt{\sum_{\mathrm{i}=1}^{\mathrm{n}}[\mathrm{x}-\overline{\mathrm{x}}]^{2} \mathrm{P}\left(\mathrm{x}_{\mathrm{i}}\right)}
\end{gathered}
$$

The variability of returns gets wider, and the risk gets greater as time goes by. Practically, this would be translated such that the longer the life of an investment asset, the higher the risk involved. Suppose that two investment project proposals were submitted to a firm for funding, with their own estimations of the profits (in hundreds of thousands of dollars) in the next five years (Table 3 and Table 4). We can expect that the financial advisors/managers would make their assessment and choice based on some measures such as the one described above.

Since the two projects will yield the same expected value, the next crucial criterion would be which of them is safer or riskier than the other. The answer would be clear at the calculation of variance $\left(\sigma^{2}\right)$ and standard deviation $(\sigma)$. The calculated results show that Project I had a smaller standard deviation (658) than Project II $(1,710)$. Project I would win for being less risky than Project II. It is clear on Figure 1. how data of Project II are dispersed over horizontally, forming a widely spread curve while they are much tighter in Project I, which shows how the outcomes are generally close to the expected value or mean.

\begin{tabular}{|c|c|c|c|c|c|c|}
\hline Years & $\begin{array}{c}\text { Predicted Profits } \\
x_{i} \\
\end{array}$ & $\begin{array}{c}\text { Probability } \\
\mathrm{P}\left(\mathrm{x}_{\mathrm{i}}\right)\end{array}$ & $\mathrm{x}_{\mathrm{i}} \mathrm{P}\left(\mathrm{x}_{\mathrm{i}}\right)$ & {$\left[x_{i}-\bar{x}\right]$} & {$\left[\mathrm{x}_{\mathrm{i}}-\overline{\mathrm{x}}\right]^{2}$} & {$\left[x_{i}-\bar{x}\right]^{2} P\left(x_{i}\right)$} \\
\hline 1 & 4,375 & .10. & 437.5 & -625 & 390,625 & $3,9062.5$ \\
\hline 2 & 4,450 & .25 & $1,112.5$ & -550 & 302,500 & 75,625 \\
\hline 3 & 4,850 & .30 & 1,455 & -150 & 22,500 & 6,750 \\
\hline 4 & 5,300 & .25 & 1,325 & 300 & 90,000 & 22,500 \\
\hline 5 & 6,700 & .10 & 670 & 1,700 & $2,890,000$ & 289,000 \\
\hline & \multicolumn{3}{|c|}{$\bar{x}=\sum_{i=1}^{5} x_{i} P\left(x_{i}\right)=5,000$} & \multicolumn{3}{|c|}{$\sigma^{2}=\sum_{i=1}^{5}\left[x_{i}-\bar{x}\right]^{2} P\left(x_{i}\right)=432,937$} \\
\hline
\end{tabular}

Table 3. Estimations of profits for 5 years in Project I

\begin{tabular}{|c|c|c|c|c|c|c|}
\hline Years & $\begin{array}{c}\text { Predicted Profits } \\
\mathrm{x}_{\mathrm{i}} \\
\end{array}$ & $\begin{array}{l}\text { Probability } \\
\mathrm{P}\left(\mathrm{x}_{\mathrm{i}}\right)\end{array}$ & $\mathrm{xP}\left(\mathrm{x}_{\mathrm{i}}\right)$ & {$\left[\mathrm{x}_{\mathrm{i}}-\overline{\mathrm{x}}\right]$} & {$\left[\mathrm{x}_{\mathrm{i}}-\overline{\mathrm{x}}\right]^{2}$} & {$\left[\mathrm{x}_{\mathrm{i}}-\overline{\mathrm{x}}\right]^{2} \quad \mathrm{P}\left(\mathrm{x}_{\mathrm{i}}\right)$} \\
\hline 1 & 2,000 & .10 & 200 & $-3,000$ & $9,000,000$ & 900,000 \\
\hline 2 & 3,500 & .25 & 875 & $-1,500$ & $2,250,000$ & 562,500 \\
\hline 3 & 5,000 & .30 & 1,500 & 0 & 0 & 0 \\
\hline 4 & 6,500 & .25 & 1,625 & 1,500 & $2,250,000$ & 562,500 \\
\hline 5 & 8,000 & .10 & 800 & 3,000 & $9,000,000$ & 900,000 \\
\hline & & \multicolumn{2}{|c|}{$\overline{\mathrm{x}}=\sum_{\mathrm{i}=1}^{5} \mathrm{x}_{\mathrm{i}} \mathrm{P}\left(\mathrm{x}_{\mathrm{i}}\right)=5,000$} & \multicolumn{3}{|c|}{$\sigma^{2}=\sum_{\mathrm{i}=1}^{5}\left[\mathrm{x}_{\mathrm{i}}-\overline{\mathrm{x}}\right]^{2} \mathrm{P}\left(\mathrm{x}_{\mathrm{i}}\right)=2,925,000$} \\
\hline
\end{tabular}

Table 4. Estimations of profits for 5 years in Project II 


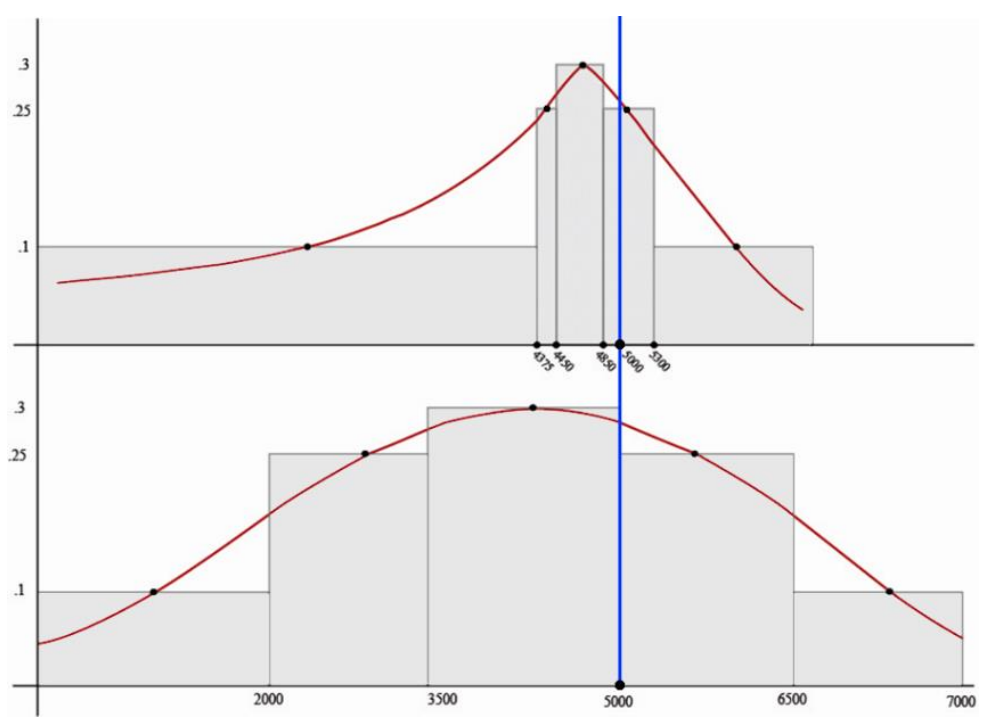

Figure 1. Data dispersion of project I vs. project II.

Assuming the distribution is normal, it would mean that:

There is a $68.26 \%$ chance that the actual outcome is within one standard deviation from the expected value. Based on the symmetry of the normal distribution, this chance is divided equally between a negative $34.13 \%$ and a positive 34.13\% (Alhabeeb, 2013; Kilka \& Weber, 2001). So, if the standard deviation is 1,710, for example, there would be a $34.13 \%$ chance that the actual value is $5,000+1,710$, and a $34.13 \%$ chance that it is $5,000-$ 1,710. So, the general range would be from 3,290 to 6,710 . The chance would increase to $95.44 \%$ within two standard deviations $(2 \times 1,710)$, which is also split equally on both sides of the mean. In this case, the chance would be $47.7 \%$ that the range of the actual outcome would be between 1,580: [5,000 - $(2 \times 1,710)]$ and 8,420: $[5,000+(2 \times 1,710)]$.

If we deal with a smaller standard deviation such as the 658 , the ranges of the actual outcome would be closer to the expected value, rendering more security and less risk. This interpretation is, of course, not limited to the discrete one, two, or three standard deviations from the mean. it would apply to any range in between. Therefore, we can find the probability of a specific outcome $\left(\mathrm{x}_{\mathrm{i}}\right)$ such as 5,500, for example. We can calculate how much of a standard deviation from the mean $(\overline{\mathrm{x}})$ this value would reveal by calculating the value of $\mathrm{Z}$ and looking up the statistical table of the normal distribution

$$
Z=\frac{x_{i}-\bar{x}}{\sigma} ; \quad Z=\frac{5,500-5,000}{658}=.76
$$

This means that if we have an actual outcome of 5,500, it will fall within a little more than three quarters of a standard deviation from the expected value. Looking at the table between .7 and .8 vertically (z-value) and under $2 \%$ horizontally, we can see that the area under the curve would be between .26 and .29 .

The second type is the Relative Measure, which is helpful when we have projects with different expected values. It requires that the standard deviations must be relative to their expected values, hence the calculation of the coefficient of variation $(\mathrm{V})$ which measures the outcome dispersion as it is related to each of the expected values individually, $V=\frac{\sigma}{\bar{x}}$. In this sense, the measure of risk would be translated into a measure of standard deviation per unit of the expected value. The relationship between the coefficient of variation and risk is still as positive. So, the criteria would be "the lower the value of the coefficient the lower the risk, and vice versa. In our absolute measure in the last example, Project II $(\sigma=1,710)$ was riskier than Project I $(\sigma=658)$ while both would yield the same expected value $(\bar{x}=5,000)$. Suppose now that Project II has an expected value of $\$ 6,000$. It would still be riskier than Project I if we compare their coefficient of variation $(\mathrm{V})$ :

$$
\mathrm{V}_{\mathrm{I}}=\frac{\sigma_{\mathrm{I}}}{\overline{\mathrm{x}}_{\mathrm{I}}}=\frac{658}{5,000}=.13 ; \quad \mathrm{V}_{\text {II }}=\frac{\sigma_{\text {II }}}{\overline{\mathrm{x}}_{\text {II }}}=\frac{1,710}{6,000}=.28
$$

where Project II revealed a higher coefficient of variation reflecting a higher risk. 


\section{Risk Aversion}

Risk aversion can be translated into people's general tendency to avoid, or at least minimize, all sorts of risk and uncertainty when they make decisions. Decision makers are described based on three major attitudes they take towards risk. A Risk Averter who would choose no risk, or at best the lowest possible level of risk. A Risk Taker who prefers to venture and gets involved in risky situations and in conditions that require a higher level of speculation in pursuit of the highest possible payoff. A Risk Neutral who is indifferent to risk, and only focuses on expected returns much more than to pay any attention to the way those returns are dispersed. (Jarrow \& $\mathrm{Li}$, 2021; Rabin, 2001). Although it has been very well established in the business world that the highest return is usually associated with the highest risk, most people, and specifically managers, are naturally risk averters, especially when larger potential losses are involved. It has been observed that even risk neutrals would turn into risk averters when large amounts of money are at stake (Barber \& Odean, 2001; Battalio et al., 1990).

Suppose that a group of people in a club decided to play a coin gamble, and since many wanted to play, the following rules were put forward: If a head turns up, the player wins $\$ 200$. If a tail turns up, the player loses $\$ 100$, and because of the competition to play, $\$ 10$ is offered to the player who gives up his turn, or basically pledges not to play. According to the attitudes towards risk, a risk averter would have no problem leaving the game and take the $\$ 10$ for doing nothing. For him, it would be an easy gain, although it is at the expense of foregoing a possibility of gaining $\$ 200$. For a risk neutral, the focus would be on the weighted average that would come out of this game. He would make his decision since in reality there would be an average gain since the amount for gain is higher than the amount for loss while both stand the same probability (50\%). In this case, the risk neutral would calculate the expected value:

$$
\mathrm{x}_{1}\left(\mathrm{p}_{1}\right)+\mathrm{x}_{2}\left(\mathrm{p}_{2}\right)=\overline{\mathrm{x}} ; \quad(200)(.5)+(-100)(.5)=50
$$

A risk taker would be the most enthusiastic to play, focusing on the highest win and he may not hesitate to play again in pursuit of that $\$ 200$.

\section{Risk Attitudes and Utility of Money}

Risk attitudes can be explained by the utility of the earned or lost money. Each attitude can be represented more accurately by the change in total utility or what we call the marginal utility. Marginal utility is generally decreasing for the risk averter, increasing for the risk taker, and constant for the risk neutral. Table 5 contains data on five possible payoffs and both total utility TU and marginal utility MU derived from them as subjectively determined by the three types of decision makers.

Table 5. Three risk attitudes based on marginal utility

\begin{tabular}{lcccccc}
\hline \multirow{2}{*}{ Payoff } & \multicolumn{2}{c}{ Decreasing } & \multicolumn{2}{c}{ Increasing } & \multicolumn{2}{c}{ Constant } \\
\cline { 2 - 7 } & TU & MU & TU & MU & TU & MU \\
\hline$-25,000$ & -6 & $/$ & -1.75 & $/$ & -5 & $/$ \\
0 & 0 & 6 & 0 & 1.75 & 0 & 5 \\
25,000 & 4 & 4 & 2 & 2 & 5 & 5 \\
50,000 & 6 & 2 & 5 & 3 & 10 & 5 \\
75,000 & 7.5 & 1.5 & 8.5 & 3.5 & 15 & 5 \\
100,000 & 8.25 & 0.75 & 13.25 & 4.75 & 20 & 5 \\
\hline
\end{tabular}

In Figure 2, We can visually observe how three managers represented by their marginal utility curves A, B, and $\mathrm{C}$ perceive their monies and assess their utilities. 


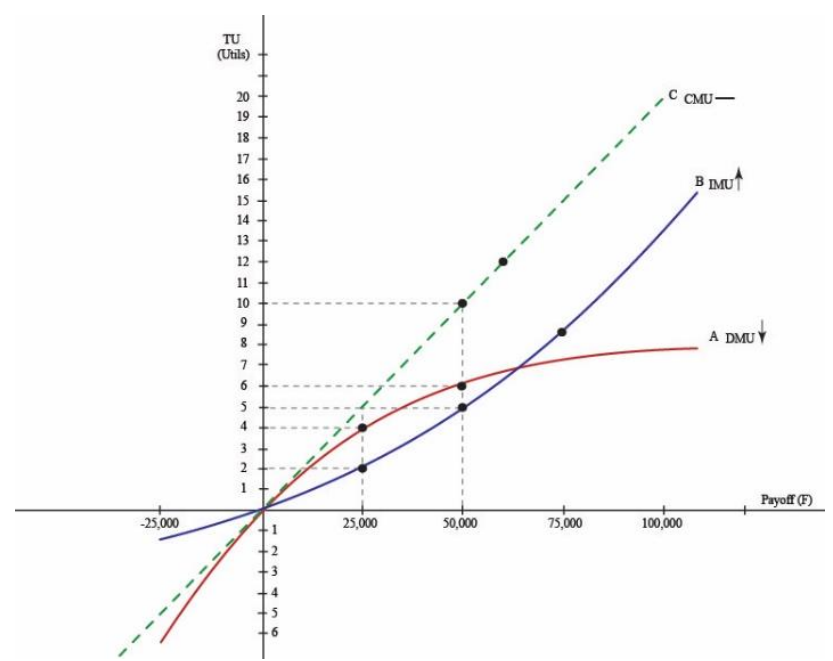

Figure 2. Utilities and payoffs of three different managers

If we take, for example, a payoff of $\$ 50,000$, it will provide a total utility of 6 utils for the risk averter represented by the diminishing marginal utility concave curve (A); provides 5 utils for the risk taker represented by the increasing marginal utility convex curve (B); and provides 10 utils for the risk neutral manager represented by the constant marginal utility straight line (C). We can observe further differences among these three managers based on their attitudes towards winning and losing money. If, for example, we consider an event that would increase the payoff from $\$ 50,000$ to $\$ 75,000$ (Table 6), how would these managers respond? The risk averter's total utility would increase from 6 to 7.5 gaining 1.5 utils; the risk taker's utility would increase from 5 to 8.5 gaining 3.5 utils; and the risk neutral's utility would increase from 10 to 15 , gaining 5 utils. The risk averter ultimately gained the least among the three from the same amount of money. Such a gain would get even less when we move them further in the payoff from $\$ 75,000$ to $\$ 100,000$. The risk averter would gain only .75 utils as compared to 4.75 utils for the risk taker and 5 utils for the risk neutral. What this theoretical approximation means is that only the risk neutral would respond proportionally to the change in the monetary payoff. He would take it dollar for dollar or dollar gained would equal dollar lost for him. It is an attitude of indifference towards risk. The table below shows that, where the percentage change in the last column is identical in both cases with the percentage change in the payoff amounts in the second column. It also shows that the risk averter's utility responds in less than proportional as compared to the change in the payoff where the third column shows .25 and .10 are less than their corresponding changes in the payoff amount, .50 and .30 respectively in the second column. As for the risk taker's utility, it responds in more than proportional to the monetary change in the payoff amount. Notice the percentage changes in the sixth column (.70 and .56) and compare them to their corresponding charges of the payoff amounts in the second column (.50 and .30) respectively. All the percentage changes were obtained by dividing the difference between the later and earlier amounts by the earlier amount

$$
\% \Delta \mathrm{x}=\frac{\mathrm{x}_{2}-\mathrm{x}_{1}}{\mathrm{x}_{1}}
$$

Table 6. Changes in attitudes based on changes in payoffs

\begin{tabular}{cccccccc}
\hline 1 & 2 & 3 & 4 & 5 & 6 & 7 & 8 \\
\hline Payoff & $\% \Delta$ & Risk Averter's & $\% \Delta$ & Risk Taker's & $\% \Delta$ & Risk Neutral & $\% \Delta$ \\
& in Payoff & Utility & & Utility & & Utility & \\
$\$ 50,000$ & & 6 & & 5 & & 10 & .70 \\
$\$ 75,000$ & .50 & 7.5 & .25 & 8.5 & .56 & 20 & .50 \\
$\$ 100,000$ & .30 & 8.25 & .10 & 13.25 & .30 & \\
\hline
\end{tabular}




\section{Expected Utility of Money vs. Expected Monetary Return}

Suppose a manager wants to invest in oil drilling, and he would face the following possibilities: 1) If no oil turns up, he will lose all the investment of $\$ 25,000$. The probability of this outcome is $80 \%$. 2) If oil is found, the payoff would be $\$ 100,000$, but this outcome is probable at only $20 \%$. The expected value of investment in oil drilling would be: $(100,000)(.20)+(-25,000)(.80)=0$

Obviously, if he decides not to drill, the expected value would be zero already. So, under this fair game, it would not matter what decision the manager makes since both, to drill and not to drill, would eventually lead to a zero outcome. In this scenario, a decision based on the expected monetary value of the payoff would not help. What would help here is to decide based on the utility of money (O'Donoghue \& Somerville, 2018; Rabin, 2000; Xin \& Frangopol, 2015). Here we would see three different assessments corresponding to three different risk attitudes, as we have seen earlier. Using the previous table of utility, we can calculate the expected value of money utility for the three managers with three attitudes:

1) For the risk averter manager, the expected value of utility EVmv would be equal to:

$$
\mathrm{EVmv}=\left(\mathrm{Ut}_{1}\right)\left(\mathrm{P}_{1}\right)+\left(\mathrm{Ut}_{2}\right)\left(\mathrm{P}_{2}\right)=(8.25)(.20)+(-6)(.80)=-3.15
$$

2) For the risk taker: $\mathrm{EVmv}=(13.25)(.20)+(-1.75)(.80)=1.25$

3) For the risk neutral: $\mathrm{EVmv}=(20)(.20)+(-5)(.80)=0$

Therefore, it is expected that the risk averter manager would decide not to drill because of the negative expected utility $(-3.15)$ as compared to the expected utility of zero in no drilling. On the contrary, the risk taker would decide to drill based on his positive expected utility of (1.25). The risk neutral manager ended up with no expected utility and therefore it is as good as no drilling.

If we know the function of the utility of money $\mathrm{U}$, such as $\mathrm{U}=400 \mathrm{~m}^{.25}$

And we know the initial amount of money (m), then we can test whether the function is increasing or decreasing. This one is an increasing function of money since the first derivative is positive:

$$
\frac{\mathrm{dU}}{\mathrm{dm}}=(.25)(400) \mathrm{m}^{-.75}=100 \mathrm{~m}^{-.75}>0
$$

And it is positive for any amount of money larger than zero. The second derivative of the function would determine the type of function for the marginal utility:

- If it is constant marginal utility, $\frac{\mathrm{d}^{2} \mathrm{U}}{\mathrm{dm}^{2}}=0$, it would indicate a neutral risk attitude.

- If it is decreasing marginal utility, $\frac{\mathrm{d}^{2} \mathrm{U}}{\mathrm{dm}^{2}}<0$, it would refer to the risk aversion attitude.

- If it is increasing marginal utility, $\frac{\mathrm{d}^{2} \mathrm{U}}{\mathrm{dm}^{2}}>0$, it would be the risk-taking attitude.

Therefore, the second derivative for our function is:

$$
\begin{gathered}
\frac{\mathrm{d}^{2} \mathrm{U}}{\mathrm{dm}^{2}}=(-.75)(100)(\mathrm{m})^{-1.75}, \text { and if } \mathrm{m}=\$ 1,000, \text { then } \\
\frac{\mathrm{d}^{2} \mathrm{U}}{\mathrm{dm}^{2}}=(-.75)(100)(1,000)^{-1.75}=-4.22
\end{gathered}
$$

which confirms that the marginal utility function is decreasing, and the decision maker would be described as a risk averter. Now, let's consider the impact of winning $\$ 500$ as well as losing $\$ 500$ on an initial amount of money of $\$ 1,000(\mathrm{~m}=1,000)$. $\mathrm{U}_{1}=400 \mathrm{~m}^{.25}=400(1,000)^{.25}=2,249.36$

If the person wins $\$ 500$, $\mathrm{m}$ would be 1,500 : $\mathrm{U}_{2}=400(1,500)^{.25}=2,489.33$, and if the person loses $\$ 500$, $\mathrm{m}$ would be 500: $\mathrm{U}_{3}=400(500)^{.25}=1,891.48, \Delta \mathrm{U}_{1-2}=\mathrm{U}_{2}-\mathrm{U}_{1}=2, .33-2,249.36=239.97$,

$\Delta \mathrm{U}_{1-3}=\mathrm{U}_{3}-\mathrm{U}_{1}=1,891.48-2,249.36=-357.88$

If this game is a coin flipping game, the expected value of utility would be obtained by:

$\mathrm{E}(\mathrm{U})=\sum \Delta \mathrm{UP}_{\mathrm{i}}=\Delta \mathrm{U}_{1}\left(\mathrm{P}_{1}\right)+\mathrm{U}_{2}\left(\mathrm{P}_{2}\right)=(239.97)(.5)+(-357.88)(.5)=-58.95$

Since the expected value of utility turns out to be negative, the decision would be not to get into this gamble. 


\section{Risk Discount and Certainty Equivalent}

The person who received $\$ 10$ as a reward for giving up the gamble is certainly a risk averter. This amount of $\$ 10$ is called certainty equivalent (CE). It is defined as the compensation which renders the player indifferent to a risky gamble. In that scenario, the expected value of the game was $\$ 50$, as the risk neutral player has considered it. The person who accepted a significantly less outcome $(\$ 10)$ is for sure a player with a definite risk aversion attitude. This would further define the risk averter as one whose certainty equivalent limit is less than the expected value of a certain risk. The difference between the expected value $\mathrm{E}(\mathrm{v})$ and the certainty equivalent (CE) is called the Risk Discount $(\mathrm{RD})$ : $\mathrm{RD}=\mathrm{E}(\mathrm{v})-\mathrm{CE}$

Risk discount shows the extent to which the expected value for a given risk is reduced to avoid such a risky prospect. In our previous example, risk discount was $\$ 40$ :

$$
\mathrm{RD}=\mathrm{E}(\mathrm{v})-\mathrm{CE}=50-10=40
$$

Figure 3 shows the certainty equivalent and risk discount as we recall the shapes of the curves for the risk averter (the diminishing marginal utility curve DMU), and for the risk neutral (the constant marginal utility curve CMU).

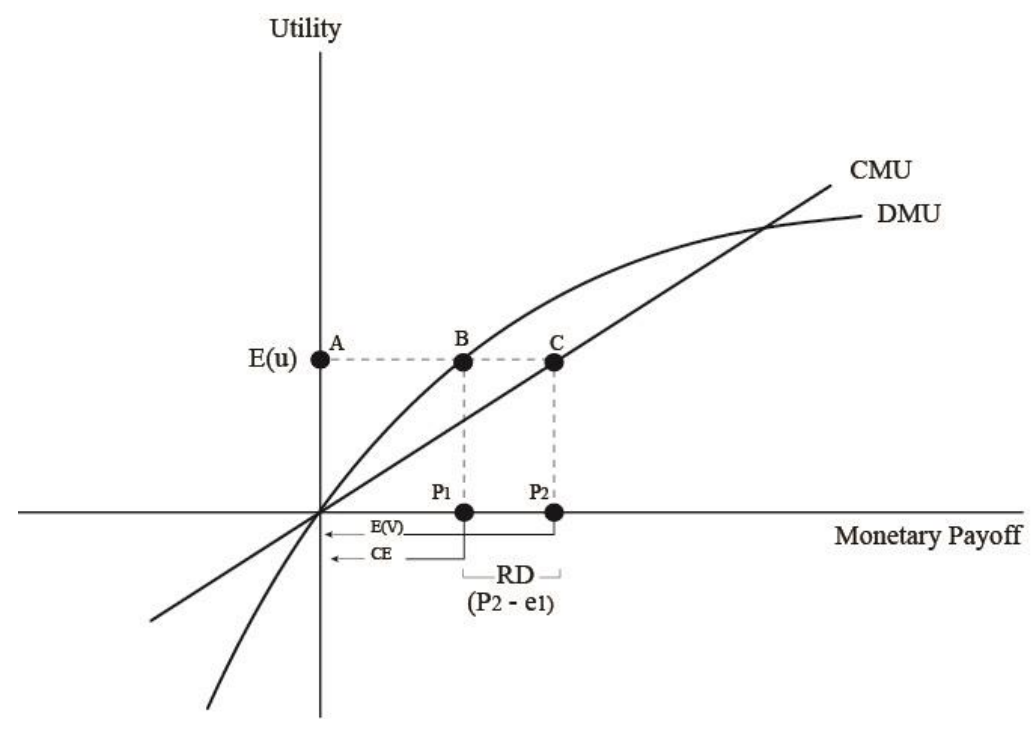

Figure 3. Certainty equivalent and risk discount

Point A represents the expected utility of the game, the level that would generate two points, $\mathrm{B}$ and C, on the risk averter and risk neutral curves, DMU and CMU respectively. From those points, we can drop verticals to see the amounts of payoff for both players. For the risk averter, point $\mathrm{P}_{1}$ would represent the certainty equivalent, and for the risk neutral, point $\mathrm{P}_{2}$ would represent the expected value. The difference $\left(\mathrm{P}_{2}-\mathrm{P}_{1}\right)$ would be the risk discount RD.

\section{Risk Impact on the Valuation Model}

When a firm wants to evaluate the worthiness of an investment project, risk factor should be among the priorities to be considered, as it affects the actual net present value NPV of the project. There are two common ways to adjust the valuation model for risk:

\subsection{Risk Premium Adjustment}

Risk premium is defined as the difference between the expected rate of return on a risky investment and the risk-free rate (Adusei, 2019; Alhabeeb, 2010; Chalamandaris \& Rompolis, 2020; Gagliardini, 2016). Let's consider three managers or financial advisors with three different attitudes about risk, as represented by the three curves on Figure 4 where risk is on the $\mathrm{x}$-axis, as it is measured by the standard deviation $(\sigma)$, and rate of return is on the vertical axis. Let's think of these curves in a way similar to the indifference curves. They depict the tradeoff between risk and return from three different attitudes towards risk. The first, RR1, represents the least risk-averse among the three. The top $\mathrm{RR}_{3}$, represents the most risk-averse, and $\mathrm{RR}_{2}$ stands in between. 


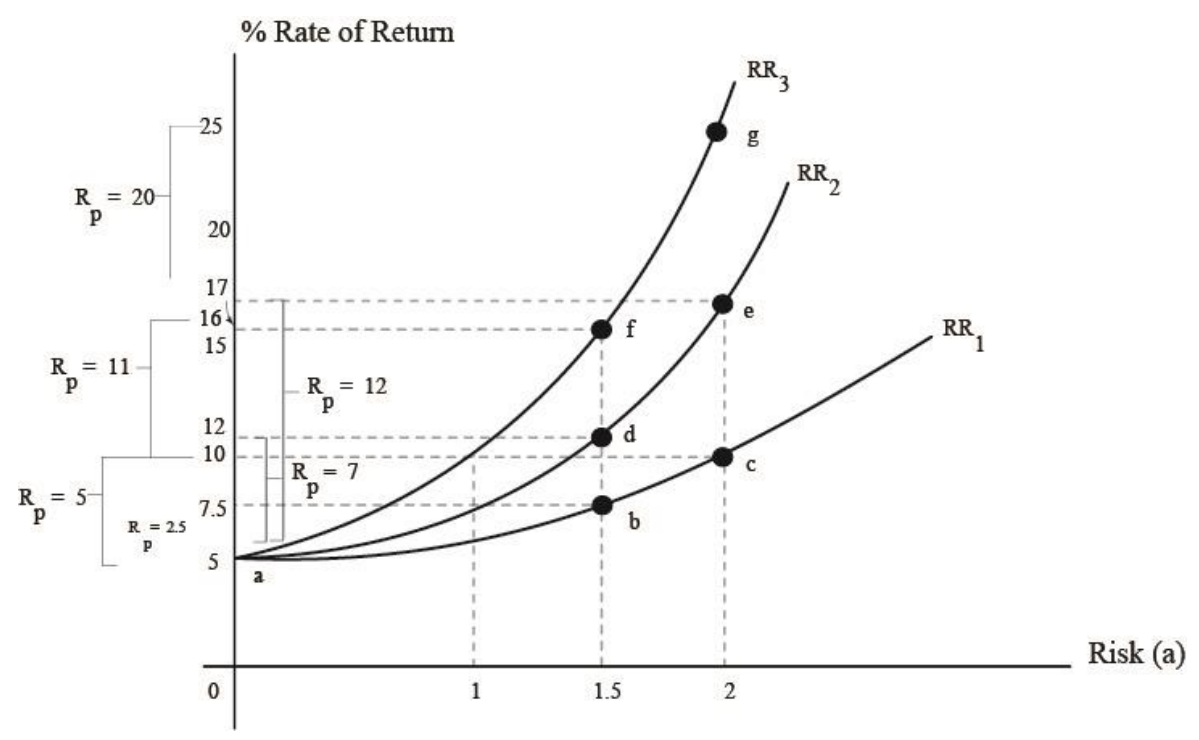

Figure 4. Three financial advisors with three different attitudes towards risk

Point a is on all curves and it shows a $5 \%$ risk-free rate (risk $=0$ ). $\mathrm{RR}_{1}$ shows a manager who is indifferent between accepting a $5 \%$ rate with no risk or taking a $1.5 \sigma$ risk to get a $7.5 \%$ return. In other words, for the added risk (from 0 to $1.5 \sigma$ ), his risk premium becomes $2.5 \%$ (7.5\% - 5\%). For the more risk-averse manager on $\mathrm{RR}_{3}$, the move to accept the additional risk of $1.5 \sigma$ would not be satisfactory unless there is a higher risk premium of $11 \%$ so that the required rate of return becomes $16 \%$. Not only that, but if the next opportunity happens to come with an additional risk of $.5 \sigma$ (such as moving from $1.5 \sigma$ to $2 \sigma$ ), the risk-averse manager on $\mathrm{RR}_{3}$ would want his

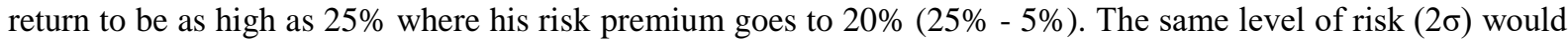
make the manager of $\mathrm{RR}_{1}$ happy to accept only $10 \%$ return making his risk premium $5 \%$ this time $(10 \%-5 \%)$. As for the moderate manager on $\mathrm{RR}_{2}$, he would accept moderate levels of risk for reasonable rates of return. He would be indifferent between risk-free rate of $5 \%$ and $10 \%$ rate with $1.5 \sigma$ risk or $17 \%$ rate with $2 \sigma$ risk. His risk premium would be $7 \%(12 \%-5 \%)$ at point $\mathrm{d}$, and $12 \%(17 \%-5 \%)$ at point e. Table 7 shows a comparison between the three positions on risk and return, and risk premium.

The different attitudes by managers towards risk would produce various risk premiums and that would be reflected on the valuation model of a firm as the risk-adjusted rate $(\mathrm{k})$ would replace the risk-free rate $(\mathrm{r})$ that is normally used in the evaluation model: $\mathrm{V}=\sum_{\mathrm{t}=1}^{\mathrm{n}} \frac{\pi_{\mathrm{i}}}{(1+\mathrm{r})^{\mathrm{t}}}$ where $\mathrm{V}$ is the value of the asset, $\pi_{\mathrm{i}}$ is the expected profit per year, $r$ is the risk free rate of return so that the value is equal to the present value of the future returns or cash flow.

Table 7. Risk premium based on return and risk attitudes

\begin{tabular}{ccccc}
\hline Risk Attitude & Point & Rate of Return $\%$ & Risk Level $(\sigma)$ & Risk Premium \% \\
\hline $\mathrm{RR}_{1}$ & $\mathrm{a}$ & 5 & 0 & 2.5 \\
least risk-averse & $\mathrm{a}$ & 7.5 & 1.5 & 5 \\
$\mathrm{RR}_{2}$ & $\mathrm{c}$ & 10 & 2 & 7 \\
moderate risk-averse & $\mathrm{a}$ & 5 & 0 & 12 \\
$\mathrm{RR}_{3}$ & $\mathrm{~d}$ & 12 & 1.5 & 11 \\
most risk-averse & $\mathrm{e}$ & 17 & 2 & 20 \\
\hline
\end{tabular}

When the firm faces the prospect of a risky project, the valuation would be adjusted to the expected risk by incorporating the firm's risk premium $\left(\mathrm{R}_{\mathrm{p}}\right)$. In this case, the net present value NPV of the project would be: 


$$
\mathrm{NPV}=\sum_{\mathrm{t}=1}^{\mathrm{n}} \frac{\pi_{\mathrm{i}}}{(1+\mathrm{k})^{\mathrm{t}}}-\mathrm{C}_{0}
$$

where $\mathrm{k}$ is the risk-adjusted rate of return, which is equal to the risk-free rate (r) used previously, plus the firm's risk premium $R_{\mathrm{p}}: \mathrm{k}=\mathrm{r}+\mathrm{R}_{\mathrm{p}}$, and $\mathrm{C}_{0}$ is the initial cost of the project. The criteria would remain such that an investment is worthwhile when the net present value (NPV) is either equal or larger than zero. NPV $\geq 0$

Suppose a managerial/financial team must decide on capital allocation for two proposed investment projects, each of which will yield profits for the next 5 years as shown in Table 8. They require initial investments of $\$ 420,000$ and $\$ 500,000$ respectively. Although the firm's cost of capital is $6 \%$, further investigation revealed certain risk elements associated with both projects.

Table 8. Returns of project A and project B for five years.

\begin{tabular}{ccc}
\hline Time & Project A cash inflows & Project B cash inflows \\
\hline Year 1 & 126,000 & 280,000 \\
2 & 126,000 & 108,000 \\
3 & 112,000 & 90,000 \\
4 & 98,000 & 80,000 \\
5 & 84,000 & 70,000 \\
Initial Investment & 420,000 & 500,000 \\
$\mathrm{r}$ & $6 \%$ & $6 \%$ \\
$\mathrm{R}_{\mathrm{p}}$ & $2 \frac{1}{2} \%$ & $3 \frac{1}{2} \%$ \\
\hline
\end{tabular}

The decision makers found it necessary to adjust for risk by assigning risk premiums $\left(R_{p}\right)$ of $2 \frac{1}{2} \%$ and $3 \frac{1}{2} \%$ to both projects respectively. The classic criterion for granting an investment has to utilize calculating the net present value using the risk-adjusted rate of return: First we calculate the net present value of the cash inflows for both projects at the time of their yields using the firm's interest rate $(\mathrm{r}-6 \%)$. Then we calculate the same net present values, using the risk-adjusted rate $(\mathrm{k})$ :

$$
\begin{aligned}
& \mathrm{k}=\mathrm{r}+\mathrm{R}_{\mathrm{p}}=.06+.025=.085 \quad \text { for Project A }=.06+.035=.095 \quad \text { for Project } \mathrm{B} \\
& \mathrm{NPV}_{\mathrm{A}}= \sum_{\mathrm{t}=1}^{5} \frac{\pi_{\mathrm{i}}}{(1+\mathrm{r})^{1}}-\mathrm{C}_{0} \\
&= \frac{\pi_{1}}{(1+\mathrm{r})^{1}}+\frac{\pi_{2}}{(1+\mathrm{r})^{2}}+\frac{\pi_{3}}{(1+\mathrm{r})^{3}}+\frac{\pi_{4}}{(1+\mathrm{r})^{4}}+\frac{\pi_{5}}{(1+\mathrm{r})^{5}}-\mathrm{C}_{0} \\
&= \frac{126,000}{(1+.06)^{1}}+\frac{126,000}{(1+.06)^{2}}+\frac{112,000}{(1+.06)^{3}}+\frac{98,000}{(1+.06)^{4}}+\frac{84,000}{(1+.06)^{5}}-(420,000) \\
&= 118,868+112,140+94,037+77,625+62,767-420,000 \\
&= 465,440-420,00=45,440 \\
& \mathrm{NPV}_{\mathrm{B}}= \frac{280,000}{(1+.06)^{1}}+\frac{108,000}{(1+.06)^{2}}+\frac{90,000}{(1+.06)^{3}}+\frac{80,000}{(1+.06)^{4}}+\frac{70,000}{(1+.06)^{5}}-(500,000) \\
&= 264,151+96,120+75,565+63,367+52,308-500,000 \\
&= 551,511-500,000=51,511 \\
& \mathrm{NPV}_{\mathrm{A}}^{\mathrm{adj}}=\frac{126,000}{(1+.085)^{1}}+\frac{126,000}{(1+.085)^{2}}+\frac{112,000}{(1+.085)^{3}}+\frac{98,000}{(1+.085)^{4}}+\frac{84,000}{(1+.085)^{5}}-(420,000) \\
&=116,129+107,031+87,685+70,714+55,864-420,000=17,423
\end{aligned}
$$




$$
\begin{aligned}
\mathrm{NPV}_{\mathrm{B}}^{\mathrm{adj}} & =\frac{280,000}{(1+.095)^{1}}+\frac{108,000}{(1+.095)^{2}}+\frac{90,000}{(1+.095)^{3}}+\frac{80,000}{(1+.095)^{4}}+\frac{70,000}{(1+.095)^{5}} \\
& =255,707+90,073+68,549+55,646+44,466-(500,000) \\
& =514,440-500,000=14,440
\end{aligned}
$$

At the normal interest rate of $6 \%$, Project B would win the approval of the financial/managerial team since its net present value $(\$ 51,511)$, is larger than that of Project A $(\$ 45,440)$. However, after considering the expected risk involved in both projects, the decision makers would give its approval to Project A due to its larger adjusted net present value of $(\$ 17,423)$ as compared to that of Project B $(\$ 14,440)$.

\subsection{Certainty-Equivalent Adjustment}

As it was explained before, certainty equivalent (CE) is the sure sum that is equal to the expected value $\mathrm{E}(\mathrm{v})$ of the risky project. The equivalency is in the utilities of both to the manager or investor, and not necessarily in their monetary values. Let's assume there is a proposal that requires the company to invest $\$ 30,000$ in a project, where the probabilities of its success and failure are 50/50 between earning $\$ 100,000$ and earning nothing, respectively. The expected value for such a project would be:

$$
\mathrm{E}(\mathrm{v})=100,000(.5)+0(.50)=50,000
$$

If the company approves the funding, it will mean that it is trading off the certainty of $\$ 30,000$ for a risky expected return of $\$ 50,000$. In fact, it means that a sure risk-free capital of $\$ 30,000$ is yielding the same utility of a risky $\$ 50,000$, hence, the term certainty equivalent to the amount of $\$ 30,000$ that would make the decision maker indifferent between the two prospects. The certainty equivalent coefficient $(\alpha)$ is the ratio between the certainty equivalent (CE) and its expected risky return $\mathrm{E}(\mathrm{v}) . \quad \alpha=\frac{\mathrm{CE}}{\mathrm{E}(\mathrm{v})}$

The certainty equivalent is subjectively determined by the decision maker and, therefore, it would be a product of how risk averse or risk taker is that decision maker. Figure 5 shows that three different attitudes towards risk would produce three certainty equivalent amounts for the same expected value of $\$ 1,000$ for a specific risky project: The most risk-averse manager on $\mathrm{RR}_{3}$ would assign $\$ 870$, the least risk-averse would assign $\$ 220$, and the moderate manager among the three would assign $\$ 460$. These cases would produce three different certainty equivalent coefficients:

$$
\alpha_{3}=\frac{870}{1,000}=.87 ; \alpha_{2}=\frac{460}{1,000}=.46 ; \alpha_{1}=\frac{220}{1,000}=.22
$$

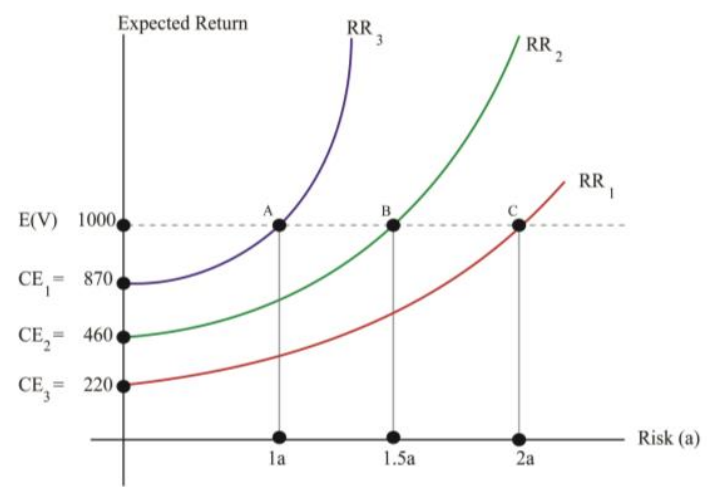

Figure 5. Risk attitudes and certainty equivalents

The risk-averse manager would value the sure risk-free money more. That is why his alpha is higher. An alpha of .87 means that each dollar of the certain money would be worth $87 \phi$, as compared to the $22 \phi$ for the risk taker. This is one reason to see why the risk taker dares to take a high risk. Alternatively, each dollar of the expected risky return is valued less $(\$ 1.15)$ for the risk-averse than for the risk taker who values his expected dollar at $\$ 4.55$. Generally speaking, the criterion for alpha is as follows: 
- When $\alpha=0$ : It is an indication that the probability of getting the expected return does not exist, and therefore the project is too risky to be pursued.

- When $\alpha=1$ : It refers to the equality between the certainty equivalent (CE) and the expected value of return of the risky project. When the manager or investor gets his return equal to what he assigns as a certainty equivalent, the project is considered risk free.

- When $0<\alpha<1$ : It is an indication that there is some level of risk. The project is riskier as $\alpha$ value is closer to zero, and less risky if it is closer to 1 . It would depend on how smaller the certainty equivalent (CE) is, as compared to the expected value of the risky return $\mathrm{E}(\mathrm{v})$.

The valuation model would be adjusted for risk by introducing $\alpha$ to the numerator of the formula as a multiplier to the expected return or profit or cash flow, while the bottom of the formula would keep the risk-free rate (r):

$$
\mathrm{NPV}=\sum_{\mathrm{t}=1}^{\mathrm{n}} \frac{\alpha \pi_{\mathrm{i}}}{(1+\mathrm{r})^{\mathrm{t}}}-\mathrm{C}_{0}
$$

Let's assume that the manager assigned certainty equivalent sums to each annual return of the five years in both projects of the last example. Table 9 shows $\alpha$ values as it is calculated by dividing the assigned certainty equivalent by the corresponding expected return.

Table 9. Expected returns and certainty equivalent for project A and project B for five years.

\begin{tabular}{ccccccc}
\hline & \multicolumn{3}{c}{ A } & \multicolumn{3}{c}{ B } \\
\cline { 2 - 7 } Time & Expected Return & Certainty Equivalent & $\alpha$ & Expected Return & Certainty Equivalent & $\alpha$ \\
\hline Year 1 & 126,000 & 123,000 & .98 & 280,000 & 240,000 & .86 \\
2 & 126,000 & 123,000 & .98 & 108,000 & 100,000 & .93 \\
3 & 112,000 & 106,000 & .95 & 90,000 & 86,000 & .95 \\
4 & 98,000 & 95,000 & .97 & 80,000 & 76,000 & .95 \\
5 & 84,000 & 82,000 & .98 & 70,000 & 68,000 & .97 \\
\hline Initial investment & 420,000 & & 500,000 & \\
r & $6 \%$ & \multicolumn{5}{c}{$6 \%$} \\
\hline
\end{tabular}

Applying those calculated alphas, we get:

$$
\begin{aligned}
\mathrm{NPV}_{\mathrm{A}} & =\sum_{\mathrm{t}=1}^{\mathrm{n}} \frac{\alpha \pi_{\mathrm{i}}}{(1+\mathrm{r})^{\mathrm{t}}}-\mathrm{C}_{0} \\
& =\frac{(.98)(126,000)}{(1+.06)^{1}}+\frac{(.98)(126,000)}{(1+.06)^{2}}+\frac{(.95)(112,000)}{(1+.06)^{3}}+\frac{(.97)(98,000)}{(1+.06)^{4}}+\frac{(.98)(84,000)}{(1+.06)^{5}}-420,000 \\
& =(116,490+109,897+89,335+75,296+61,514)-420,000 \\
& =452,532-420,000=32,532 \\
\mathrm{NPv}_{\mathrm{B}} & =\frac{(.86)(280,000)}{(1+.06)^{1}}+\frac{(.93)(108,000)}{(1+.06)^{2}}+\frac{(.95)(90,000)}{(1+.06)^{3}}+\frac{(.95)(80,000)}{(1+.06)^{4}}+\frac{(.97)(70,000)}{(1+.06)^{5}}-500,000 \\
& =(227,170+89,391+71,787+60,199+50,739)-500,000=499,286-500,000=-714
\end{aligned}
$$

Considering the expected risk for both projects in terms of estimating the certainty equivalent and calculating $\alpha$ for each return in every year revealed that Project A is more worthwhile for yielding a positive value of $\$ 32,532$ while Project B went into a negative net value.

\section{Conclusion}

The study stated its objective as to revisit and clarify major concepts and important theoretical constructs that have been, sometimes, used in a confusing way and misleading applications with erroneous results. Therefore, it was necessary to differentiate between risk and uncertainty and shed a light on sub-terms such as total and partial uncertainty and related constructs such as risk aversion, uncertainty aversion, and ambiguity aversion. The focus was on risk for its practical value, being the core construct directly related to the financial and managerial decisions. For that, risk was detailed by its sources, measurement, people's attitudes towards risk, and the impact on expected return and economic utility. Discussed also was the risk discount and risk premium, certainty 
equivalence, and the impact on valuation model. Clear definitions were given, and numerical examples were solved, with graphical illustration.

\section{References}

Adusei, M. (2019). The finance-growth nexus: Does risk premium matter? International Journal of Finance and Economics, 24(1), 588-603. https://doi.org/10.1002/ijfe.1681

Alhabeeb, M. J. (2010). Mathematical finance. Hoboken, NJ: Wiley Publications. https://doi.org/10.1002/9781118106907

Alhabeeb, M. J., \& Moffitt, J. L. (2013). Managerial economics: a mathematical approach. Hoboken, NJ: Wiley Publications.

Analytis, P. P., Wu, C. M., \& Gelastopoulos, A. (2019). Make - or - break: chasing risky goals or settling for safe rewards? Cognitive Science, 43(7). https://doi.org/10.1111/cogs.12743

Baker, D., \& Carson, K. (1975). The two faces of uncertainty avoidance: attachment and adaptation. Journal of Behavioral and Applied Management, 12(2), 128-141. https://doi.org/10.21818/001c.17633

Baltussen, G., van den Assem, Martijn, J., \& van Dolder, D. (2016). Risky choice in the limelight. Review of Economics and Statistics, 98(2), 318-332. https://doi.org/10.1162/REST_a_00505

Barber, B. M., \& Odean, T. (2001). The Internet and the Investor. Journal of Economic Perspectives, 15(1), 41-54. https://doi.org/10.1257/jep.15.1.41

Battalio, R. C., Kagel, J. H., \& Jiranyakul, K. (1990). Testing between alternative models of choice under uncertainty: some initial results. Journal of Risk and Uncertainty, 3(1). https://doi.org/10.1007/BF00213259

Bell, D. E. (1985). Disappointment in decision making under uncertainty. Operations Research, 33(1), 1-27. https://doi.org/10.1287/opre.33.1.1

Chalamandaris, G., \& Rompolis, L. S. (2020). Recovering the market risk premium from higher - order moment risks. European Financial Management: The Journal of the European Financial Management Association, 27(1), 147-186. https://doi.org/10.1111/eufm.12287

De Groot, K., \& Thurik, R. (2018). Disentangling risk and uncertainty: when risk-taking measures are not about risk. Frontiers in Psychology, 9, 1-7. https://doi.org/10.3389/fpsyg.2018.02194

Ellsberg, D. (1961). Risk, ambiguity, and the savage axioms. Quarterly Journal of Economics, 75, 643- 669. https://doi.org/10.2307/1884324

Fama, E. F., \& French, K. R. (1992). The cross-section of expected stock returns. Journal of Finance, 47(2), 427-65. https://doi.org/10.1111/j.1540-6261.1992.tb04398.x

Gagliardini, P., Ossola, E., \& Scaillet, O. (2016). Time-varying risk premium in large cross-sectional equity data sets. Econometrica, 84(3), 985-1046. https://doi.org/10.3982/ECTA11069

Jarrow, R., \& Li, S. (2021). Concavity, stochastic utility, and risk aversion. Finance and Stochastics, 25(2), 311-330. https://doi.org/10.1007/s00780-021-00448-5

Kahn, B. E., \& Sarin, R. K. (1988). Modeling ambiguity in decisions under uncertainty. Journal of Consumer Research, 15, 265-272. https://doi.org/10.1086/209163

Kahneman, D., \& Tversky, A. (1979). Prospect theory: an analysis of decision under risk. Econometrica, 47, 263-291. https://doi.org/10.2307/1914185

Kilka, M., \& Weber, M. (2001). What determines the shape of the probability weighting function under uncertainty? Management Science, 47, 1712-1726. https://doi.org/10.1287/mnsc.47.12.1712.10239

Kim, H. W., Kang, J. I., Namkoong, K., Jhung, K., Ha, R. Y., \& Kim, S. J. (2015). Further evidence of a dissociation between decision-making under ambiguity and decision-making under risk in obsessivecompulsive disorder. Journal of Affective Disorders, $176,124$. https://doi.org/10.1016/j.jad.2015.08.064

Knight, F. H. (1921). Risk, Uncertainty and Profit. New York, NY: Sentry Press. https://doi.org/10.1017/cbo9780511817410.005

O'Donoghue, T., \& Somerville, J. (2018). Modeling risk aversion in economics. Journal of Economic Perspectives, 32(2), 91-114. https://doi.org/10.1257/jep.32.2.91

Rabin, M. (2000). Risk aversion and expected-utility theory: A calibration theorem. Econometrica, 68(5), 
1281-92. https://doi.org/10.1111/1468-0262.00158

Rabin, M., \& Thaler, R. (2001). Anomalies: Risk aversion. Journal of Economic Perspectives, 15(1), $219-32$. https://doi.org/10.1257/jep.15.1.219

Tversky, A., \& Kahneman, D. (1992). Advances in prospect theory: Cumulative representation of uncertainty. Journal of Risk and Uncertainty, 5, 297-323. https://doi.org/10.1007/BF00122574

Xin, R. Z. W., \& Frangopol, D. M. (2015). Risk matrix: Integrating risk attitudes based on utility theory. Risk Analysis, 35(8), 1437-1447. https://doi.org/10.1111/risa.12400

\section{Copyrights}

Copyright for this article is retained by the author(s), with first publication rights granted to the journal.

This is an open-access article distributed under the terms and conditions of the Creative Commons Attribution license (http://creativecommons.org/licenses/by/4.0/). 